\title{
Jovellanos, dramaturgo romántico
}

RUSSELl P. SEBOLD

Universidad de Pennsylvania

Hace unos diez años, un hispanista norteamericano llegó a la acertada conclusión de que «el Torcuato de El delicuente honrado es en todos los sentidos un héroe tan romántico como el Rugiero de La conjuración de Venecia» '. Sin embargo, son todavía más asombrosos los paralelos que existen entre la célebre comedia lacrimosa de Jovellanos y Don Álvaro o la fuerza del sino del Duque de Rivas, tanto más cuanto que nunca se han estudiado ni mencionado. No me interesan como tales los estudios fuentísticos, mas sí creo que la identificación de las numerosas coincidencias entre la comedia sentimental de Jovellanos y el drama de Rivas servirá para ilustrar el romanticismo de la obra objeto de este trabajo, la cual, por otra parte, se produce en una época que empieza ya a ser conocida como la del primer romanticismo español. Con el propósito indicado, veamos rápidamente cuáles son las principales ilaciones argumentales, ambientales y caracteriológicas que se dan entre las obras de Gaspar Melchor de Jovellanos y Ángel de Saavedra.

La acción de ambas obras se supone acaecida en el siglo XVIII, no siendo frecuente en el teatro romántico decimonónico la utilización

Michael D. Mc. Gaha, "The Romanticism of La conjuración de Venecia», Kentucky Romance Quarterly, XX (1973), 235-242: 
de tal marco histórico. El rey es el mismo, con la única diferencia de que Carlos es todavía rey de Nápoles en Don Álvaro, pero es ya Carlos III de España en El delincuente. En cada obra la acción es complicada por un nuevo edicto excesivamente duro contra los duelos; cada protagonista - Torcuato, luego Álvaro- es el primero en violar el edicto, y en cada caso el rey quiere aplicar la nueva ley al primer reo en forma severa para fijar un sano precedente legal y penal. Cada héroe mata involuntariamente a un marqués; y cada uno de ellos huye o proyecta su huida. En las dos piezas se da un amor prohibido que sobrevive al rompimiento, por el asesinato, de un lazo familiar reconocido por la Iglesia y el Estado: Torcuato mata al marido de Laura; Álvaro mata al padre de Leonor. En diferentes momentos de las respectivas acciones dramáticas cada héroe se siente desgarrado entre sus intentos de reconciliarse con sus futuras víctimas y su apremiante necesidad de defender su propio honor. Los dos héroes son bastardos; Torcuato es hijo de un indiano; Álvaro es indiano y medio indio de sangre. Tanto Álvaro como Torcuato, al mismo tiempo que son criminales, son encarnaciones de un nuevo concepto del bien moral que se opone a la moralidad tradicional. Es decir, que los dos son buenos salvajes, o salvajes nobles, a lo Rousseau, por haberse visto obligados a vivir al margen de la sociedad conservadora guiándose por su natural instinto de bondad.

En ambos microcosmos dramáticos, la oposición de las instituciones sociales constituye el destino, aunque cada protagonista apostrofa al destino como si fuera el cielo y maldice a la vez su nacimiento. «El cielo me ha condenado a vivir en la adversidad. ¿Qué desdichado nací!»-se lamenta Torcuato- $(\mathrm{DE}, \mathrm{I}, 3)^{2}$. «¿Qué carga insufrible / es el ambiente vital / para el mezquino mortal / que nace en sino terrible! —exclama Álvaro-. [ ... ] Este mundo, / iqué calabozo profundo / para el hombre desdichado / a quien mira el cielo airado / con su ceño furibundo!» (DA, III, 3). En cada obra un personaje o varios quieren echarse a las plantas del benigno rey Carlos con el fin de implorar el perdón regio para el honrado asesino. En el primer parlamento de El delincuente se presagia casi toda la acción de la obra; en las dos primeras escenas de Don Álvaro se predice todo lo que sucederá después. Incluso se encuentra, en el texto de Rivas, en un parlamento de Leonor

2 Citaré El delincuente honrado y Don Álvaro respectivamente por las siglas DE y $\mathrm{DA}$, indicando los números de los actos o jornadas con números romanos y los de las escenas con números arábigos. 
relativo a Álvaro, un eco del título de la obra de Jovellanos: «Aunque inocente, manchado / con sangre del padre mío / está» (DA, II, 7). Aunque inocente, manchado; es decir, aunque honrado, delincuente. Pocas veces cabe señalar tantas semejanzas para apoyar una tesis de deuda literaria entre dos obras, y descubriremos todavía otros paralelos entre ellas al estudiar las brillantes innovaciones técnicas de la comedia sentimental de Jovellanos.

No sólo se anticipa Jovellanos a las líneas argumentales de un conocido drama del segundo romanticismo - este tipo de fenómeno puede producirse por la mera casualidad entre obras pertenecientes a movimientos completamente dispares-; sino que El delicuente honrado (1773) se compone y se estrena en la primera década marcada por una notable producción literaria de índole romántica: también son del decenio de 1770 la Fiesta de toros en Madrid de Nicolás Fernández de Moratín; los Ocios de mi juventud (poemas como «En lúgubres cipreses») de Cadalso; las Noches lúgubres del mismo Cadalso; El precipitado de Trigueros; el perdido Tristemio, diálogos lúgubres a la muerte de su padre de Meléndez Valdés; la oda $A$ la mañana, en mi desamparo y orfandad, también de Batilo, etc. Y más que por meras coincidencias argumentales con dramas individuales de épocas posteriores (aunque no habría que descontar éstas totalmente), El delincuente honrado es romántico por las técnicas y la cosmovisión que comparte con otras obras de la misma tendencia literaria, tanto dieciochescas como decimonónicas. La comedia lacrimosa nace del seno del teatro neoclásico, mas por su desenvolvimiento trae a la memoria esa víbora legendaria de antaño que al nacer rompía los ijares de su madre dejándola muerta.

Hablemos primero del carácter romántico de Torcuato. Su carácter difiere radicalmente del de los personajes neoclásicos, pues tanto en la tragedia como en la comedia de abolengo grecolatino, el análisis de los defectos psicológicos es un elemento fundamental, pero Torcuato no tiene ni un solo defecto moral. En tragedias como la Fedra de Racine, la Raquel de García de la Huerta, la Numancia destruida de López de Ayala, el desenlace trágico se motiva por pasiones incestuosas, obediencias precipitadas, faltas de confianza en las propias fuerzas; en comedias como las de Molière y Moratín toda la acción gira en torno al hecho de que los personajes centrales son tacaños, misántropos, mentirosos, hipócritas, etc. (incluso en esas comedias en las que se estudia una institución social, en lugar de alguna variante del carácter humano, como El sí de las niñas, suele haber en segundo plano una tesis psi- 
cológica, por ejemplo, la chifladura de doña Irene en la referida comedia de Leandro Moratín). Mas Torcuato - subráyese el contraste absoluto- es, en palabras del mismo texto, «un hombre honrado, cuyo delito consiste sólo en haberlo sido» (DE, III, 10). Aquí habla don Justo. Pero por si hubiera alguna duda, tres escenas más tarde, la misma idea se pone en boca de Torcuato: «El honor - dice- [ ... ] fue la única causa de mi delito» (DE, IV, 3). Torcuato es moralmente perfecto; así sólo pudo ser llevado a matar al marqués de Montilla por la totalidad de las circunstancias sociales en las que se encuentra enmarcado, y por lo demás venía desde hacía mucho luchando noblemente contra esas circunstancias.

Los criterios para los juicios morales en la comedia lacrimosa son totalmente contrarios a los que habían sido tenidos en cuenta en los géneros clásicos. En la tragedia y la comedia los valores tradicionales de la sociedad existente son la norma. En Tartuffe de Molière, por ejemplo, el célebre hipócrita de ese nombre es objeto de la crítica porque las mañas emanadas de su carácter representan amenazas a todas las instituciones básicas de la sociedad: el matrimonio, la Iglesia, el derecho de la propiedad personal, la obediencia filial, etc. En Raquel, por mucho que el liberalismo de García de la Huerta le lleve a compadecerse de la triste suerte de la bella hebrea, ésta tiene que morir porque bajo su influencia peligran la religión oficial del Estado español y el poder del monarca que reina merced a un derecho divino derivado de esa religión. Ahora bien: los términos de la oposición moral entre protagonista y sociedad se invierten en la comedia sentimental, y esto es quizá lo que principalmente acerca el nuevo género tragicómico al drama romántico.

Los juicios morales expresados en El delincuente honrado no señalan la culpabilidad de un individuo - patrón neoclásico-, sino que ensalzan la ejemplaridad de Torcuato como hombre individual, de alma noble y sensible, superior por su misma naturaleza a toda intención torcida, así como a todos aquellos con quienes está destinado a convivir. Cuando tal hombre asesina a un prójimo, es evidente que la responsabilidad reside en otro lugar, probablemente en el sistema social y penal, y tal individuo no es juzgable sino haciéndose una excepción a esas leyes que rezan inflexiblemente con los demás. He aquí un curioso eco de Rousseau, quien mantenía que existen ciertas almas «si ex- 
traordinaires, qu'on n'en peut juger sur les règles communes ${ }^{3}$. No es ya el individuo quien tenga que conformarse con los valores de la sociedad para lograr la perfección moral, sino la colectividad la que tendrá que tomar en cuenta la bondad inherente del criminal excepcional. El hombre de corazón puro, el buen salvaje rousseauniano, comete una fechoría únicamente cuando le lleva a ello la sociedad, corrompida por la satánica competencia, o sea mal uso del instinto primario de la propia conservación con que nacemos todos los hombres. No está lejos ya el momento en que, extremando la interpretación literaria de esta radical doctrina, Zorrilla podrá salvar al burlador que Tirso condenó a las llamas del infierno, según he hecho ver en el capítulo segundo de mi libro Trayectoria del romanticismo español ${ }^{4}$.

Mas las ideas de Rousseau, quien quería despertar de nuevo el instinto compasivo secundario del hombre - de ahí en parte lo lacrimoso de la comedia sentimental- no son las únicas que determinan el viraje total de las normas morales en el mundo y el teatro setecentistas. El pensamiento moral contenido en la obra De l'Esprit des lois de Montesquieu está aludido, por ejemplo, en El delincuente honrado. Y una de las principales inspiraciones para la comedia lacrimosa de Jovellanos fue el tratado Dei delitti e delle pene (1764) de Cesare Bonesana, marqués de Beccaria. Se ha señalado que la crítica beccariana del uso del tormento para arrancar las confesiones a los presuntos reos está reiterada en El delincuente; y se ha observado a la vez que la moraleja de toda la obra de Gaspar Melchor está preludiada en el siguiente pasaje de Beccaria sobre los duelos: «El mejor método de precaver este delito es castigar al agresor, entiéndase al que ha dado la ocasión para el duelo, declarando inocente al que sin culpa suya se vio precisado a defender lo que las leyes no aseguran, que es la opinión» ${ }^{5}$. Sin embargo, para nuestro propósito, lo más significativo de este pasaje es que también sirve para absolver de toda culpa a los asesinos en esos casos en que sobreviven a los duelos los agredidos.

Esto, junto con la actitud sentimental de Beccaria al querer arrancar de las garras de una justicia voraz a los inocentes falsamente acusa-

3 Jean-Jacques Rousseau, Julie, ou la Nouvelle Hélö̈se, première partie, lettre LX.

4 Rusell P. Sebold, Trayectoria del romanticismo español. Desde la Ilustración hasta Bécquer, Barcelona, Editorial Crítica, 1983, pp. 66-71.

5 Beccaria, De los delitos y de las penas, trad. (1774) de Juan Antonio de las Casas, «El Libro de Bolsillo», núm. 133, Madrid, Alianza Editorial, 1968, p. 43. 
dos o a los culpables cruelmente torturados, tendrá consecuencias profundas. Beccaria tiende a mirar al reo como víctima, como figura noble, ejemplar, mal comprendida, y tiende también a unirse a él en oposición a todos los ciudadanos estrictamente observantes de la ley; pues «si sosteniendo los derechos de la humanidad y de la verdad invencible - escribe el gran penalista-, yo contribuyese a arrancar de los dolores y angustias de la muerte a alguna víctima infeliz de la tiranía o de la ignorancia [ ... ], las bendiciones y lágrimas de un solo inocente me consolarían del desprecio de los hombres» ${ }^{6}$; fascinante muestra de ese odio cósmico, puntuado por la ternura, que será característico del fastidio universal. Es más: según Beccaria, los malhechores no son la mayoría de las veces moralmente culpables, porque las instituciones educativas mantenidas por la sociedad son defectuosas. Y efectivamente, incluso en el caso del provocador del duelo en El delincuente honrado, el marqués de Montilla, se identifica como factor importante una «perversa educación» (DE, IV, 3). En fin, por no haberse compadecido del reo educándole para que se rehabilite como ciudadano modelo, la sociedad se ha hecho más censurable que el reo; conclusión que llevará a muchas reformas en el código penal, no siempre felices.

Sin embargo, las consecuencias más radicales y más positivas de tal humanitarismo son las literarias, porque en la esfera de la imaginación nos hemos identificado aún más estrechamente con los facinerosos, y estéticamente los hemos rehabilitado por completo; porque de su confusa y contradictoria suerte hemos derivado un nuevo y muy rico concepto del héroe en el teatro y en la novela. El asesino Torcuato en El delincuente honrado y el casi incestuoso y suicida Amato en El precipitado de Trigueros, son los primeros ejemplos del reo héroe en la literatura española, pero tendrán una larga progenie de cuya extraña psicología híbrida dependerá el ambiente moral así como el principal encanto humano de las obras más logradas que se producirán por lo menos hasta 1860 . Sentimos una sorprendente compasión y una aún más sorprendente - a veces exquisita - admiración por los asesinos y calaveras materialistas Saldaña en Sancho Saldaña de Espronceda y Javier en De Villahermosa a la China de Pastor Díaz, por el conspirador Rugiero en La conjuración de Venecia de Martínez de la Rosa, por el desalmado pirata en Canción del pirata de Espronceda, por el tres veces asesino Álvaro en Don Álvaro del duque de Rivas, por el joven inces-

6 Ibid., p. 45. 
tuoso Ferrando en El paje de García Gutiérrez, por los estupradores don Félix de Montemar en El estudiante de Salamanca de Espronceda y don Juan en Don Juan Tenorio de Zorrilla, por los adúlteros cuyas cuitas se cuentan en el Canto a Teresa de Espronceda, etc., etc. Mas sin ningún lugar a la duda, lo más fascinante de la mayoría de estos personajes románticos -cualidad que Jovellanos presagia hasta con su título oximorónico- es el satanismo veteado de buena fe.

Lo que pasa es que confluyen y se oponen en estos personajes dos moralidades antagónicas: cada una de estas figuras es, ora un hombre manchado por el pecado original y responsable por su libre arbitrio de sus propios actos, ora un hombre libre de toda culpa por su nacimiento en el estado inocente por la naturaleza y por la culpabilidad colectiva de la sociedad. Cada héroe romántico es, ya un demonio, ya un ángel, según le miremos desde el punto de vista de la tradición judeocristiana, o desde el de la nueva conciencia moral de los Rousseau y los Beccaria. Creo que no hay ningún ejemplo más patente de esto que el de don Álvaro. Don Alfonso, el tercero de los tres marqueses de Calatrava que el indiano Álvaro mata, representante de la moralidad del Establecimiento, y el propio indiano y mestizo Álvaro, que entre los indios creció, como fiera se educó (DA, V, 9) y goza así de los beneficios de la educación negativa rousseauniana, se expresan - cosa sorprendente a primera vista- en los mismísimos términos. En el Convento de los Ángeles, en las escenas que preceden al duelo final, don Alfonso dirige estas palabras a don Álvaro: «el cielo (que nunca impunes / deja las atrocidades / de un monstruo, de un asesino, / de un seductor, de un infame), $/$ por un imprevisto acaso / quiso por fin indicarme / el asilo donde a salvo / de mi furor os juzgaste» (DA, V, 6). Subrayo las voces atrocidades y monstruo, porque varias páginas más adelante don Álvaro a su vez dirige la siguiente interrogación a don Alfonso: «¿Eres monstruo del infierno, / prodigio de atrocidades?» (DA, V, 9).

La cosa queda muy clara con la yuxtaposición de estos pasajes: cada uno de estos aventureros es en una pieza el dechado de virtud de un sistema y el demonio del sistema contrario. De ahí la obsesionante y perenne complejidad que nos fascina en los perscnajes románticos, sobre todo en los de cepa heroica, como Tediato, Amato, Torcuato, Rugiero, Saldaña, Álvaro, etc., en quienes predomina difícilmente, sobre el papel de demonio del sistema antiguo, el otro papel de atrayente encarnación del bien según el nuevo sistema naturalista. Sobre todo, nos seduce la lucha interior del héroe romántico al pugnar por mantener 
su carácter de personificación del bien universal frente a su hondo temor de ser el réprobo más execrable en toda la historia del hombre desde la Creación. Ahora bien: todo esto se realiza ya en forma brillante en El delincuente honrado. El buen ciudadano, el buen amigo, el buen esposo, el filósofo, el hombre de bien Torcuato se confiesa con su cónyuge Laura revelándole a ésta por vez primera que él es el asesino de su primer marido, el marqués de Montilla: «Pues este delincuente, este hombre proscripto, desdichado, aborrecido de todos, y perseguido en todas partes $[. .$.$] soy yo mismo» (DE, II, 2). Por este parlamento de$ Torcuato también se hace evidente la estrecha relación que existe entre la ambivalencia moral del héroe romántico y la sensación de aislamiento, rechazo e incurable fastidio universal característicos de semejante personaje. Me refiero a las palabras subrayadas en el pasaje que acabo de reproducir.

El perfil satánico de Torcuato se representa, en efecto, con la misma palabra que usó después el duque de Rivas para describir esa vertiente en don Álvaro: monstruo; y en ambas obras hay dos monstruos, aunque el esquema es diferente. «Soy un monstruo que está envenenando tu corazón y llenándolo de amargura» -dice el asesino Torcuato dirigiéndose a su dolorida esposa (DE, II, 5)-. «Soy un monstruo que le ha dado la vida para arrebatársela después» - dice refiriéndose a Torcuato su padre el magistrado don Justo, quien en la juventud fue burlador y abandonó a la madre del virtuoso culpable durante su gravidez (DE, IV , 9) - . Mas el antiguo burlador es a la vez un filósofo de corazón noble igual que el asesino, y en los espíritus de ambos se da una feroz guerra entre la moralidad vieja y la nueva. Unas palabras muy sentidas de Justo, dichas a su desafortunado hijo, aluden a la esencial bondad de éste, juzgada de acuerdo con el nuevo sistema dieciochesco, y su culpa indeleble, examinada con arreglo a las prescripciones del sistema tradicional: «Tu virtud me encanta - le dice a Torcuato el filosófico alcalde de casa y corte-, y tus discursos me destrozan el corazón» (DE, IV, 3).

En El delincuente honrado hay penas a escoger y lágrimas a pasto, pues el llanto en lugar de la risa es el principal instrumento de la retórica de este género cómico. Los trozos más conmovedores son, empero, los que relacionan la emoción, no meramente con algún infortunio inherente a la situación dramática, sino con la ya indicada ambivalencia moral en lo más hondo del alma de Torcuato. «iAh! —dice Torcuato refiriéndose a su criado-, no sabe toda la aflicción de mi alma» (DE, 
I, 2). Más adelante, en una escena de mucha pasión y compasión, se apunta que Torcuato «levanta los ojos al cielo y suspira» (DE, II, 5). Anselmo, cuyo bello carácter de amigo es lástima no haya espacio para analizar, comparte toda la experiencia psicológica del virtuoso asesino y comenta así el estado de ánimo de Torcuato a raíz del duelo y sus bodas con Laura: «Un continuo remordimiento empezó a destrozarle el corazón» (DE, III, 7). Luego, como es tan profunda la pena de Torcuato, y como la dimensión virtuosa de los bifrontes héroes románticos depende de su calidad de hijos de la naturaleza universal, se proyecta la aflicción del protagonista sobre el plano cósmico. El buen don Justo se halla perplejo ante el despiadado destino de su hijo: «¿Conque tu inocencia, tus virtudes, los ruegos de un amigo, los tiernos suspiros de una esposa, las lágrimas de un padre y el sentimiento universal de la naturaleza, nada pudo librarte de la muerte, de una muerte tan acerba y tan ignominiosa?» (DE, V, 4; el subrayado es mío).

En vista de la ubicuidad de la emoción en El delincuente, también es menester considerarla en relación con otros elementos fundamentales de la obra: el melodrama, el tiempo, el espacio. La comedia lacrimosa es como una ópera en la que la emoción es la música. Es muy conocida la íntima ilación entre la ópera y el melodrama, y fue justamente en el último cuarto del siglo XVIII en el que se separaron estas dos formas de espectáculo, acentuándose mucho más en el melodrama que en la ópera los elementos de la acción, la violencia, los caracteres exagerados y la extravagante reacción emocional. Pues bien, en El delincuente honrado, el leitmotiv emocional, como una gran oleada de música, lo lleva todo tras sí desde el primer amago de peligro para Torcuato en la primera escena hasta recibirse el indulto real en la última. No hay nadie que resista a esta oleada. Era tal el noble aspecto de su inocente prisionero, que «hasta los centinelas, viendo su generosidad, lloraban como unas criaturas» (DE, III, 6) - dice el sirviente de Torcuato-. Sin embargo, no se captaría toda la fuerza del leitmotiv emocional si no se ordenara, como la música, en relaciones temporales muy especiales.

La unidad de tiempo se maneja de tal forma en El delincuente honrado, que los episodios parecen sucederse unos a otros con una rapidez. melodramática ya romántica. En realidad, no es sólo la emoción, sino la emoción y la rapidez juntas, lo que lo lleva todo tras sí. El espectador o lector, así como los agonistas del conflicto dramático, llegan jadeantes al final de la acción. La brevedad de las escenas contribuye a la impresión de la rapidez, pero las frecuentes referencias a la hora son 
aún más importantes para la creación de esta impresion. Para apreciar debidamente la gran innovación en el uso de los datos sobre la hora en El delincuente, hace falta tener presente que Luzán advierte a los dramaturgos de su siglo «que el poeta calle enteramente el tiempo de la acción, y no acuerde jamás al auditorio las horas que van pasando [... ], ni ofrezca a la vista cosa alguna de la cual se pueda venir en conocimiento del tiempo que pasa por la fábula ${ }^{7}$. Lejos de acatar este precepto, Jovellanos se refiere diecisiete veces a la hora, ya directa, ya indirectamente, por boca de sus personajes, así como en las acotaciones, y aparece el mismo reloj varias veces en escena, a saber: «(Sacando el reloj). Las siete y cuarto»; «idejar la cama a las siete de la mañana!»; «Dijo que iba a la misa, y que volvía al instante» (Acto I); «Desde las siete de la mañana [don Justo] está zampado en la cárcel»; «si acaso no está aquí al mediodía, no se le aguarde a comer»; «vuelva después de las dos»; «Señor, las doce han dado ya»; «Señores, la sopa está en la mesa»; «vamos a comerla antes que se enfríe»; «lo demás lo descubrirá el tiempo» (Acto II); «Yo trataré de volver a buen tiempo»; «Tanta prisa! ¡Tanta precipitación!» (Acto III); «La escena es de noche» (Acto IV); «La escena es de día»; «(Sacando el reloj). Ya no me queda esperanza alguna»; «se oye el reloj que da las once»; «Señor [ ... ], la hora ha dado» (Acto V). Emoción y rapidez temporal unen sus fuerzas, y el resultante vendaval provoca las acciones, así como la apasionada expresión de la angustia de los personajes ante lo inexorable del decretado suplicio de Torcuato.

La interpretación más liberal de la unidad de tiempo autorizada por los comentaristas de la poética clásica excede a las famosas veinticuatro horas. Según Luzán, «por aquel pequeño exceso que permite Aristóteles, han alargado este espacio a treinta horas, y aun algunos a dos días» ${ }^{8}$. Ahora bien: Jovellanos observa la unidad de tiempo solamente de acuerdo con este concepto liberal del precepto clásico, pues la acción de El delincuente honrado comienza poco antes de las siete y cuarto de una mañana y termina poco después de las once de la próxima mañana: algo más de veintiocho horas. Éste podría parecer, en efecto, un muy pequeño exceso. En cambio, si se compara el tiempo dramático

7 Ignacio de Luzán, La poética o reglas de la poesía en general y de sus principales especies, ed. de Russell P. Sebold, «Textos Hispánicos Modernos», núm. 34 [ahora: «Punto Omega», núm. 286], Barcelona, Editorial Labor, 1977, p. 463.

8 Ibíd., pp. 460-461. 
de la presente obra con el de las comedias de Iriarte y Moratín, se verá cuán revolucionario es El delincuente en el contexto del teatro dieciochesco: en esas otras obras sólo trancurren de dos a diez horas en las vidas de los personajes, porque sus autores procuran guiarse en lo posible por la más estricta recomendación luzanesca de que el número de horas imaginarias de la fábula coincida con las tres a cuatro horas que suele durar la representación en las tablas. Además, lo que es observar la unidad de tiempo con deseo de conseguir una verosimilitud basada en la lógica del reloj, no hay ni un asomo de semejante espíritu de observancia en El delincuente honrado.

La unidad de tiempo para Jovellanos no es sino un trampolín para llegar con un valiente salto a algo enteramente nuevo: se crea una tensión entre la observancia de la letra del precepto -sólo su letra-y una evidente voluntad de violarlo, señalada por las numerosas referencias a la hora. Por esta tensión la acción parece más larga, más compleja de lo que es; parece desbordar, por todos los lados, de los confines habituales del drama neoclásico. La aceleración de los sucesos es uno de los medios y una de las consecuencias del logro de un nuevo género de drama. No es ya la razón, el análisis de rasgos psicológicos cognoscibles entre límites espaciotemporales reducidos, lo que nos ha de convencer de la realidad del acontecer dramático, sino la rapidez engañadora de ese acontecer. No parece darnos tiempo de poner en tela de juicio la posibilidad física y psicológica de tanta acción y tanta pasión en tan poco tiempo.

Mas he aquí otro engaño y otra tensión arquitectónica en la obra, la cual se da entre su acción en realidad sencilla y el aspecto complicado de esa misma acción. Con los novelescos antecedentes del argumento a los que aluden los personajes, con el viaje a la Corte que Torcuato proyecta, con el viaje de Anselmo entre Segovia y el Real Sitio de San Ildefonso, etc., la acción parece compleja; pero lo que es acción escenificada, hay muy poca: se prende por equivocación a Anselmo, y se le suelta; se prende a Torcuato, se le sentencia, y se le pone en libertad al recibirse el perdón del rey — no hay más-. Y aun algo de esto sucede entre bastidores. Sin embargo, en la apariencia del simultáneo desborde del tiempo y la acción, tenemos - repito-importantes síntomas de un nuevo teatro en el que la ilusión depende, no ya de la razón, sino de la imaginación, un nuevo teatro romancesco, según apellidaba el se- 
vero Moratín a ciertas comedias poco ajustadas al arte ${ }^{9}$. Al mismo tiempo dependen igualmente de esos desbordes las reacciones emocionales de los personajes ante sus situaciones vitales: en efecto, la completa conjugación de ilusión y emoción es lo más característico de la nueva variante teatral que Jovellanos está ensayando.

En la comedia del Siglo de Oro prevalece la peripecia; en el teatro neoclásico predomina el carácter; en los grandes dramas románticos del XIX volverá a prevalecer la peripecia, mas compartirá con la reacción emocional, no su papel de móvil, pero sí su cualidad de síntoma sine qua non de lo que es teatro en la segunda época romántica; y es precisamente a este nuevo consorcio entre circunstancia y emoción al que se adelanta Jovellanos en su técnica. El desplazamiento del análisis psicológico por la reacción emocional está al mismo tiempo en consonancia con la teoría de Diderot sobre el género lacrimoso, a la que voy a referirme más adelante.

En la representación del espacio dramático se produce otra tensión - entre la observancia de la letra del precepto y la voluntad de descubrir un concepto enteramente nuevo del espacio-. Luzán reconoce la existencia de interpretaciones poco rigurosas de la unidad de lugar, «pretendiendo algunos - dice - que la escena pueda figurar toda una ciudad y algunas leguas al derredor» ${ }^{10}$; y es únicamente esta interpretación libre de la referida regla lo que Jovellanos toma en cuenta. Pues utiliza tres decoraciones diferentes: en el acto I la escena representa «el estudio del corregidor, adornado sin ostentación»; en el acto II estamos en «una sala decentemente adornada», quizás en la misma casa (pero nótese el contraste entre las descripciones: «adornado sin ostentación» - «decentemente adornada»); en el acto III volvemos al estudio del corregidor; y -mutación principal de toda la pieza- en los actos IV y $\mathrm{V}$ nos encontramos en «el interior de una torre del alcázar», primero, de noche con la luz de una sola bujía, y luego, de día, con acompañamiento de «música militar lúgubre». Se trata de una ilusión espacial que no depende enteramente de la razón, sino que ya también la imaginación juega su papel importante. Esto se hace doblemente claro cuando se considera que hay una fina adecuación artística entre las cualidades

9 Véanse los ejemplos citados en mi estudio «Lo romancesco, la novela y el teatro romántico», en Cuadernos Hispanoamericanos, núm. 348, junio 1979, pp. 515-536; o en mi ya citado libro Trayectoria del romanticismo español, pp. 137-163.

10 Luzán, Poética, ed. cit., p. 465. 
físicas del lugar y las psicológicas de la acción figurada en ese lugar. El estudio del corregidor y sus viejos librotes de derecho, en gran folio, encuadernados en pergamino, sus procesos y otros papeles legales, simbolizan la amenaza de pena capital que se cierne sobre la cabeza de Torcuato; y en efecto esta decoración sirve por la mayor parte para escenificar conversaciones entre parejas de personas directamente afectadas por esa amenaza y que hablan de ella en esos momentos: Torcuato y su criado Felipe, Torcuato y su amigo Anselmo, Justo y Simón, Laura y Simón, Laura y Anselmo. En cambio, en el acto II, cuando hay mayor apariencia de normalidad y parece posible otra vez hacer vida de familia, estamos lógicamente en la «sala decentemente adornada», con grupos más grandes de actores.

Pero lo más innovador desde el punto de vista de lo romántico es el cambio al lúgubre ambiente de la torre cuando el destino de Torcuato parece sellado. El simbolismo de los ambientes tétricos será característico de dramas románticos decimonónicos como Alfredo, Don Álvaro, El Trovador, El paje, etc. El ejemplo más ilustrativo, sin embargo, es el exagerado de la famosa parodia dramática ; ¡Ella!!! ... y ¡ijÉl!!!, incluida en el artículo de Mesonero Romanos, de 1837, sobre «El romanticismo y los románticos». Los títulos de los seis actos de ii iElla!!! ... y i iÉl!!! ... -resúmenes de sus respectivos espisodios- son: Un crimen; El veneno; Ya es tarde; El panteón; ¡Ella!; ;Él!. Y las decoraciones correspondientes son: salón de baile, bosque, la capilla, un subterráneo, la alcoba y el cementerio.

El lector atento sabe que El delincuente honrado también contiene otras decoraciones que rivalizan por lo sombrías con las de cualquier obra del teatro romántico posterior: se trata de decoraciones cuyo carácter aterrador no depende tanto de la ilusión creada por Jovellanos, como del poder creativo de la imaginación de las propias personas dramáticas. En las primeras escenas, cuando Torcuato se propone huir para evitar la vergüenza que su ajusticiamiento representaría para su querida Laura, el leal Anselmo le pregunta: «¿Quieres que te siga? ¿Que vayamos juntos hasta los desiertos de la Siberia?» (DE, I, 3). Por si la perspectiva de este lejano refugio no fuera bastante infausta, la afligida esposa de Torcuato le dice: «Huye, huye al instante de este funesto clima donde te persigue el infortunio» (DE, II, 7). Típico romántico, Torcuato se halla entre dos vacíos, uno lejano y otro cercano, mas veamos cómo él mismo visualiza ese vacío lejano al que proyecta su fuga. «Voy a huir de ti para siempre - dice hablando con Laura-, y a esconder 
mi vida detestable en los horribles climas donde no llega la luz del sol, y donde reinan siempre el horror y la oscuridad» (DE, II, 5). Se trata de un paisaje del alma, una Siberia psicológica más bien que geográfica, un país muy a propósito para los interminables paseos mentales de quien sufre el fastidio universal.

El paisaje infernal que Torcuato se imagina sesenta y dos años antes del estreno del Don Álvaro del duque de Rivas sería tan adecuado como la decoración de riscos inaccesibles, malezas, truenos y relámpagos que se emplea como fondo para el célebre parlamento final del satánico y virtuoso suicida mestizo Álvaro cuando se arroja desde lo más alto de un escarpado promontorio: « ¡Infierno, abre tu boca y trágame! ¡Húndase el cielo, perezca la raza humana; exterminio, destrucción...!» (DA, V, 11). Torcuato parece ya añorar estos paisajes olvidados por la mano del Creador. Corazón puro, inocente, de un hijo de la naturaleza a lo Rousseau, pero con telón de foro tenebroso, siniestro. En su Década epistolar, de 1781, el duque de Almodóvar observa que los argumentos de las comedias lacrimosas derivan por la mayor parte de novelas ${ }^{11}$ —observación que se repite en varias revistas de la época-; y en efecto, el contraste entre alma virtuosa y fondo luctuoso, macabro, es lo más típico del roman noir o novela gótica de fines del setecientos y principios del ochocientos, como se desprende de los mismos títulos de esas emocionantes ficciones: Emelina, la huérfana del castillo; Celia en el desierto; Huérfano en el Rin; Los niños de la Abadía, etc. Nótese que en estas novelas se utilizan ya paisajes amenazantes (desiertos, ríos), ya alguna especie de arquitectura tétrica o aciaga (castillos, abadías); y recuérdese, en El delincuente honrado, el horrible clima sin sol imaginado por Torcuato, así como ese funesto «interior de una torre del alcázar».

Veremos otras influencias y tendencias novelescas que como la presente todavía dejarán su impronta en el drama romántico decimonónico, mas tengamos en cuenta que la oposición entre alma sensible y medio nefasto que por un lado estremece deliciosamente a los lectores de todas las épocas y por otro lado parece tan característica del romanticismo manierista del siglo XIX, es en el fondo un fenómeno muy dieciochesco. En primer lugar, el contradictorio placer que así nos procu-

11 Francisco María de Silva [seud. de Pedro de Luján, duque de Almodóvar], Década epistolar sobre el estado de las letras en Francia (ed. príncipe: Madrid, Imprenta de Sancha, 1781), 2. ${ }^{a}$ ed., Madrid, Sancha, 1792, pp. 252, 270. 
ramos es una experiencia humana que no era posible explicar adecuadamente antes que Locke y sus sucesores hubiesen descubierto las delicadas conexiones entre nuestras almas, nuestros sentidos y nuestras circunstancias materiales. En mi libro sobre Cadalso, llamé ya la atención sobre la siguiente observación de 1699, debida al conde de Shaftesbury: «Donde se puede mantener una serie o sucesión continua de tiernos y amables afectos, aun en medio de espantos, horrores, penas y dolores, la emoción es todavía agradable. Seguimos contentos hasta con este melancólico aspecto o sentido de la virtud. Su belleza se sostiene bajo una nube y en medio de calamidades circundantes [ ... ] da el deleite más sublime ${ }^{12}$. (No es quizá sorprendente que ya en 1709 , en otro ensayo, el mismo Shaftesbury hable de la pasión romántica).

La frecuentación del esquema de personajes de corazón tierno contrastados con medios lóbregos, inhóspitos, puede al mismo tiempo ser reflejo ambiental de la ambivalencia moral del héroe romántico que ya estudiamos. Por fin, en estrecha relación con las líneas de Shaftesbury y la doble moralidad del protagonista romántico, es necesario señalar que el referido contraste entre carácter y medio es consecuencia también del acento cada vez más fuerte que los dramaturgos, los novelistas y los poetas escriben sobre la pureza moral de personajes que encarnan las cualidades del hijo de la naturaleza o buen salvaje rousseauniano; porque tal tipo es mucho más fácil de retratar en forma conmovedora si se lo presenta acosado por lo satánico y sombrío, es decir, como uno de los términos de un tajante contraste entre inocencia y crueldad. En cualquier caso, la intención es poner a prueba nuestra sensibilidad y nuestras glándulas lacrimales, y realmente se le hace cada vez más fácil y apetecible al lector del Delincuente asentir a estas palabras de Torcuato: «Si las lágrimas son efecto de la sensibilidad del corazón, ; desdichado de aquel que no es capaz de derramarlas!» (DE, I, 3).

En su reseña de El trovador (1836) de García Gutiérrez, Larra escribe lo siguiente sobre la inesperada hazaña del entonces novel poeta dramático: «Ha imaginado un plan vasto, un plan más bien de novela que de drama, y ha inventado una magnífica novela» ${ }^{13}$. Con la voz no-

12 Anthony Ashley Cooper, Earl of Shaftesbury, Characteristics of Men, Manners, Opinions, Times, ed. de John M. Roberson, Indianapolis, Bobbs-Merril, 1964, t.I, p. 297. El trozo citado a continuación, entre paréntesis, viene del t. II, p. 4.

13 Mariano José de Larra, Artículos completos, ed. de Melchor de Almagro San Martín, Madrid, Editorial Aguilar, 1944, p. 410. 
vela Larra alude a esas extravagantes redes de peripecias inopinadamente encadenadas que marcan la enorme diferencia entre obras románticas como El trovador y el drama de líneas clásicas. La polaridad entre drama clásico y drama romántico, así como la aparición de este último, suponen la aceptación para el teatro, por varias generaciones de dramaturgos, del concepto que Boileau había mantenido, no del arte escénico, sino de la novela, como he demostrado en mi artículo «Lo romancesco, la novela y el teatro romántico» ${ }^{14}$. Me refiero a los siguientes versos de Boileau, que cito por la primera traducción española de 1787: «Disculpa en la novela todo tiene, / basta si la ficción nos entretiene; / mucho rigor impertinente fuera; / mas la escena razón pide severa, / y la justa decencia ha de guardarse» ${ }^{15}$. Ahora bien: ningún antecedente más claro y legítimo del juicio de Larra sobre el plan novelesco de $E 1$ trovador hay que la autocrítica jovellanesca contenida en El delincuente honrado; ningún documento más apto para la ilustración del extraño influjo inverso de la Poética de Boileau sobre el drama romántico hay tampoco que la aludida serie de cinco sarcasmos puestos en boca del intransigente corregidor don Simón, hombre de mentalidad conservadora tanto para la literatura como para el derecho.

El personaje don Simón representa el punto de vista neoclásico riguroso; y en sus comentarios negativos sobre la acción de la obra en marcha tenemos en forma irónica un agudo análisis de innovaciones muy positivas, así como un inconcuso indicio de que Jovellanos hace tales innovaciones con plena conciencia de su radicalismo. Para la debida interpretación del primero de los sarcasmos de don Simón, es menester recordar que la comedia del Siglo de Oro es de índole más bien novelesca por su complejidad argumental, su temática y su ambiente. Pues bien, Torcuato, triste por la huida que planea y por la necesidad de confesarse antes con Laura, expresa su pasión por su esposa con toda la elocuencia amorosa de otra época, y ella responde en el mismo estilo. Lo cual ocasiona esta pulla de Simón: «¡Bueno! ¡Lindo! No lo dijeran me-

14 En Cuadernos Hispanoamericanos, núm. 348, espec. p. 529 y sigs.; o en Trayectoria del romanticismo, espec. p. 155 y sigs.

15 Juan Bautista Madramany y Carbonell, El arte poética de Nicolás Boileau Despreau [sic], traducida del verso francés al castellano, ilustrada con un prólogo y notas del traductor, Valencia, Josep y Tomás de Orga, 1787, pp. 50-51 [«Dans un roman frivole aisément tout s'excuse; / C'est assez qu'en courant la fiction amuse; / Trop de rigueur alors serait hors de saison: / Mais la scène demande une exacte raison; / L'étroite bienséance y veut être gardée» (canto III, vv. 119-123)]. 
jor dos amantes de Calderón» (DE, II, 1). Quiere decirse que, en oposición a la crítica neoclásica sobre los supuestos excesos de la escuela de Calderón, tenemos otra vez, en El delincuente, un teatro de tendencia novelesca que, aunque sea sólo en la superficie, se parece en algo no obstante al del siglo anterior. Las tres próximas ironías de Simón se refieren todas al pasmoso giro que van tomando los acontecimientos; Simón es enemigo de todo melodrama. El criado Felipe viene a informar a don Simón de que Torcuato ha ido al alcázar a confesar su culpa para libertar a Anselmo, falsamente detenido por la muerte del marqués. El comentario del neoclásico Simón es el que sigue: «iJesús! ¡Hoy todos andan locos en mi casa!» (DE, III, 6). Después Simón se expresa en el mismo tono, no ya sobre la novedad de la prisión de Torcuato, sino sobre sus efectos no menos trastornadores: «iEste mozo nos ha perdido! Mi casa está hecha una Babilonia; todos lloran, todos se afligen, todos sienten su desgracia» (DE, IV, 6).

En la penúltima escena de El delincuente honrado, Simón, por unas palabras que oye cambiarse entre Laura y Justo, descubre con indecible sorpresa que Torcuato es hijo del magistrado que ha tenido que sentenciarle a muerte. El comentario del neoclásico Simón sobre tan melodramática agnición se verbaliza así: «¿Su padre? ¿También tenemos ésa?» (DE, V, 6). Evidentemente, en este parlamento juega un papel importante el sentido del humor de Jovellanos, quien con la cáustica pregunta de Simón logra insinuar a la vez la idea de que el encanto de estas anagnórisis para el espectador está en razón inversa de lo cursis y trilladas que son. Luego, en la misma escena, todas estas ironías - la retórica amorosa calderoniana, la casa llena de locos, la casa hecha una Babilonia y el increíble parentesco entre juez y reo- se resumen en otra nueva observación de Simón todavía más clara y concluyente que las anteriores: «Señores, cuanto pasa parece una novela» (DE, V, 6).

Larra habría comprendido perfectamente la lógica de este chiste; y el uso de la voz novela para designar una acción extravagante revela la profunda conciencia jovellanesca de que su innovación en el teatro depende del acatamiento en sentido inverso del precepto de Boileau sobre la oposición entre técnica teatral y técnica novelística. La rebeldía de los dramaturgos románticos, en la medida en que tal palabra sea exacta, viene implícita ya en la poética del teatro clásico.

En mi ya citado estudio sobre la novela y los orígenes del teatro romántico, he investigado con detenimiento la sinonimia entre las voces novela, novelesco y romance, romancesco en los últimos decenios 
de la centuria decimoctava; y se utilizaba entonces este último adjetivo (romancesco) para formular la misma clase de juicio literario que Jovellanos expresa por boca del corregidor con el sustantivo novela. Considérese, por ejemplo, el resumen parcial que da Moratín de Lo que va de cetro a cetro, $y$ crueldad de Inglaterra de José de Cañizares: «Pasan seis años entre la segunda y la tercera jornada. Eduardo refiere al conde de Feria cómo le llevaron a la bóveda de su familia creyéndole muerto; cómo pudo salir de allí, y cómo halló en la orilla del mar una gruta y una mina, que por fortuna iba a parar precisamente al jardín de la prisión de Estuarda: todo romancesco, y de aquello que no sucede jamás» ${ }^{16}$. En el artículo indicado, llamo la atención sobre el hecho de que a fines del siglo XVIII existían así en la lengua castellana dos posibilidades para el desarrollo de una terminología para el romanticismo, basada, ora en la familia léxica de romance, ora en la de novela.

Demostróse en tal forma que España estaba en ese momento, en la teoría teatral, a la altura de los demás países europeos, no obstante que esa terminología autóctona sería abandonada después debido a la adopción del adjetivo internacional, de origen inglés, romántico. Mas, por muy importantes que sean la teoría y la terminología, la técnica llevada a la práctica en obras individuales lo es mucho más para medir el progreso de una determinada tendencia literaria en un país y período determinados. En El precipitado (1773) de Trigueros se utilizan interesantísimos recursos literarios que no es posible describir sino como románticos: esto lo estudié en las primeras páginas de un artículo de tema general, «El incesto, el suicidio y el primer romanticismo español», de $1973^{17}$. Merced al presente análisis de otra comedia sentimental rigurosamente contemporánea de El precipitado, tenemos aún mayor derecho a afirmar que a partir del último cuarto del siglo XVIII el teatro español cuenta entre sus alternativas auténticas y viables la forma romántica, ya bien definida en ese momento en la praxis de escritores de talento.

Resta un aspecto por considerar: la influencia de la teoría de Diderot relativa a la comedia lacrimosa; pues el drama romántico está anticipado no solamente en la práctica de los dramaturgos de la escuela la-

16 Leandro Fernández de Moratín, Obras póstumas, Madrid, Rivadeneyra, 1867-1868, t. III, p. 166. El subrayado es mío.

17 Fn Hispanic Review, XLI (1973), 660-692; o en Trayectoria del romanticismo espa$\tilde{n} o l$, pp. 109-136. Me refiero en particular a las diez primeras páginas de este trabajo. 
crimosa, sino también en la teoría de esa escuela, según quedaba expuesta con anterioridad a la composición de El delincuente. Es sabido que Diderot enfoca la técnica del género lacrimoso como una reacción en contra de la tragedia, sobre todo en contra de esos interminables y fríos monólogos que servían para la narración de los antecedentes del argumento, la puesta en escena y el análisis psicológico. "Tant que dure la tirade - escribe Diderot-, l'action est suspendue pour moi; et la scène reste vide» ${ }^{18}$. Para Diderot vale más la presencia inmediata del individuo, un individuo que represente una profesión o un parentesco familiar que nos resulte significativo; lo importante es sentir íntimamente cómo ese personaje sufre por causa de sus circunstancias, las cuales a la par que influyen en él, lo contienen como si formaran el fondo de un cuadro mural que captara lo esencial de su existencia con sus formas, sus colores y sobre todo sus emociones. El drama constará así de una serie de pinturas pantomímicas o cuadros animados en los que los parlamentos no deberán ser demasiado largos; o dicho de otro modo, el drama perfecto reunirá situaciones muy variadas, de las que el pintor pudiera sacar otras tantas pinturas.

Miraremos varios cuadros en El delincuente, mas por de pronto consideremos las consecuencias de tal afán pictórico para la forma dramática. La voluntad de exhibir diferentes cuadros y la consecuente necesidad de nuevos trasfondos llevarán forzosamente a frecuentes mutaciones y al abandono de la unidad de lugar en cualquier sentido estricto. Se escribirá un nuevo acento sobre la peripecia debido a la perpetua precisión de llevar la acción a diferentes locales o fondos pictóricos, $\mathrm{y}$ como resultado se producirá una marcada tendencia a abandonar también las unidades de acción y tiempo. Impartir mensajes morales con el ejemplo lacrimoso y preferir decoraciones, o sea cuadros de tonalidad lúgubre y fatídica, son como el anverso y reverso de la misma moneda. Recurriendo a las lágrimas como instrumento didáctico se da cada vez más importancia a la reacción emocional del individuo ante las inesperadas situaciones de esa acción nuevamente complicada, y he aquí los principales rasgos del drama romántico derivados tan claramente de las ideas de Diderot como de las otras teorías y condiciones que examinamos anteriormente. En relación con la insistencia de Diderot en el mí, y la escena queda vacía»]. 
papel del parentesco en el desarrollo de la comedia lacrimosa, deberá notarse también el sugerente hecho de que las relaciones entre padres e hijas, entre padres e hijos, entre madrastras e hijos, entre madres e hijos, entre hermanos, etc. juegan un papel igualmente importante en dramas románticos del ochocientos como La conjuración de Venecia, Don Álvaro, Alfredo, El trovador, El paje, Los amantes de Teruel, Don Juan Tenorio, etc.

Existe un estrecho paralelo entre la comedia lacrimosa y la pintura de Jean-Baptiste Greuze, maestro de lo patético burgués, de cuyos lienzos se ocupa Diderot en varios Salones entre 1759 y 1769: por un lado, tenemos un drama en lienzo; por otro, cuadros en acción, pero siempre con la misma insistencia en la corrección de la injusticia a través del sentimentalismo. Sería iluminativo comparar ejemplos de la pintura patética de Greuze con cuadros escénicos tomados de la comedia sentimental francesa o española, pero creo más sencillo buscar nuestro término de comparación en un texto literario: se trata de un cuadro natural, muy a lo Greuze, que Diderot describe a base de una experiencia personal, relacionándolo a la vez, en sus Entretiens sur «Le Fils naturel», con los efectos que el autor de comedias lacrimosas debe lograr. «Una campesina del pueblo que ve usted entre aquellas dos montañas - dice Diderot hablando con Dorval- y cuyas casas levantan sus tejados sobre los árboles, mandó su marido a casa de sus parientes, que moraban en una aldea vecina. Este desventurado fue allí matado por uno de sus cuñados. El día siguiente yo entré en la casa donde había ocurrido el accidente. Allí vi un cuadro y escuché unas palabras que no he olvidado. El muerto estaba tendido en un lecho. Sus piernas desnudas pendían fuera del lecho. Su mujer desgreñada estaba en tierra. Ella tenía los pies de su marido en las manos; y anegándose en lágrimas, y con una acción que las arrancaba a todo el mundo, decía: « ‘Ay! , cuando te mandé aquí, no pensaba que estos pies te llevasen a la muerte». ¿Cree usted que una mujer de otro rango hubiera estado más patética? No. La misma situación le habría inspirado el mismo discurso. Su alma habría sido la de aquel momento; y lo que es preciso que el artista halle, es lo que todo el mundo diría en semejante caso, lo que nadie oirá sin reconocerlo inmediatamente en sí mismo ${ }^{19}$. Ruego al lector tenga presente el vocablo que he subrayado en este pasaje.

19 Ibíd., pp. 1248-1249. 
En El delincuente honrado son frecuentes los cuadros en acción que recuerdan, ya la pintura patética de la escuela de Greuze, ya los infinitos grabados sentimentales que adornan las novelas y obras dramáticas impresas en los últimos decenios del setecientos y los primeros del ochocientos, alguna vez muy cursis, eso sí, pero no por eso menos conmovedores. Debido a esta semejanza se le ocurren sin esfuerzo al contemplador de los cuadros jovellanescos posibles títulos o pies para éstos, del mismo estilo que los que se estampan debajo de los grabados lacrimógenos de esa época. Veamos cuatro ejemplos.

El acto I se abre con un cuadro fatídico: a la fría luz del alba, solo en el estudio del corregidor, «con semblante inquieto» (DE, I, 1), rodeado de viejos librotes de derecho y papeles relativos a los castigos ejemplares, Torcuato medita sobre la triste suerte que le espera por haber matado al por otra parte indigno primer marido de Laura. La fisonomía del reo, el fondo del cuadro, toda la composición expresa la misma idea. Presentimientos de una muerte injusta podría ser su pie. El próximo cuadro que contemplaremos tendría a la fuerza que titularse $\mathrm{La} \mathrm{reu-}$ nión a deshora. El fondo es el interior de la lúgubre torre del alcázar; magistrado y reo de muerte - los trajes indican estas condiciones- acaban de reconocerse respectivamente como padre e hijo; el reo, de rodillas, le besa la mano a su padre; y los continentes de ambos respiran esa mezcla de sublime goce y profunda pena tan en boga entonces; pues a Torcuato se le ve «con gran ternura y llanto», según las acotaciones, y a Justo «con extremo dolor y ternura» (DE, IV, 3). En cualquiera de estos ejemplos imaginemos que se para el reloj, que se congela la acción; tendremos un cuadro de composición perfecta.

Al penúltimo ejemplar de lo pictórico patético en $E l$ delincuente quisiera titularlo Amanecer del dolor, y tiene un interés especial, no sólo por sugerir la composición de un cuadro, sino por contener también una de las inspiraciones de esa exquisita elocuencia natural que según Diderot es común, en situaciones idénticas, a todas las clases sociales. A Laura la vemos desgreñada, llorosa, con actitud furiosa, caída al suelo; y en el fondo habrá que suponer que se figura una ventana del alcázar por la que se descubre un campanario en el que suena la hora funesta y en la distancia un cadalso. Recuérdense las palabras de la viuda en el cuadro de Diderot: « $\mathrm{A} A y$ !, cuando te mandé aquí, no pensaba que estos pies te llevasen a la muerte». Pues bien, Laura, loca y desespera$\mathrm{da}$, al querer ir a unirse con su adorado reo de muerte en el cadalso, dice: «Tu sangre corre ya, derramada... iAh!, voy a detenerla» (DE, 
$\mathrm{V}, 5$ ). Difícilmente se encontraría ejemplar más aventajado de este género de elocuencia espontánea brotada de la misma esencia de la situación emocional. «Este melancólico silencio llena mi alma de luto y de pavor» - dice don Justo en la misma escena, creyendo ya muerto a Torcuato, aunque sin haber recibido ninguna noticia concreta-. Subráyese la voz silencio, que aparece en el mismo momento en que se nos expone el cuadro de Laura loca: es como si Jovellanos quisiera con ella puntuar la cualidad muda o estática, el silencio, de la representación plástica de la realidad, que él emula escénicamente.

Con la última muestra de esta galería jovellanesca se introduce otro nuevo elemento pictórico: el díptico. Lo sucedido en el alcázar con Laura y lo sucedido en la plaza, según lo cuenta el Escribano en la escena siguiente, son en realidad acciones simultáneas; en cada caso, en el mismo momento de «melancólico silencio», la acción toma la forma de un cuadro; y en el segundo caso, reaparece, en efecto, esta misma frase, «melancólico silencio», para recalcar a un mismo tiempo la calidad muda del lenguaje pictórico y la relación díptica entre las dos pinturas escénicas. El nuevo cuadro es panorámico, y su pie podría ser El ídolo indultado (ídolo, porque Torcuato, como todo héroe rousseaunianoromántico, es la sinopsis de las aspiraciones morales del pueblo). Toda la ciudad está reunida en la plaza del alcázar; Torcuato está en lo más alto del cadalso; el verdugo va a descargar el fatal golpe -el momento de melancólico silencio-; pero al mismo tiempo las caras de la multitud, algunas desfiguradas por el más hondo dolor, otras risueñas con el regocijo, revelan que se han escuchado simultáneamente la campana que había de señalar la muerte del reo y una voz - la de Anselmoque viene gritando: «iPerdón, perdón!» $(\mathrm{V}, 6)$; confusión redentora.

Dudo que ningún cultivador de la comedia sentimental haya sacado más provecho de la teoría de Diderot relativa a los cuadros escénicos. La genialidad de Jovellanos en el manejo de éstos representa otro indispensable antecedente del teatro romántico decimonónico, en el que es conocidísima la frecuencia con que las decoraciones y la colocación de los actores en el escenario simulan la composición de un cuadro, y en el que aun es de uso frecuente la misma palabra cuadro; todo lo cual se practica de modo muy consciente en la obra de dramaturgos como el Duque de Rivas, quien era, además, pintor. Después de todo, la famosa parodia de drama romántico incluida en El romanticismo y los románticos de Mesonero es una obra en seis actos y catorce cuadros. En El delincuente honrado se anticipa toda la diversidad de los cuadros 
dramáticos del teatro romántico posterior: cuadros que representan la casa, la ciudad, la naturaleza, grupos pequeños de agonistas, multitudes. Por ejemplo, sin antecedentes como el pueblo reunido en la plaza para ver el triste espectáculo de la decapitación de Torcuato, sería mucho más difícil explicar el acto IV de La conjuración de Venecia, el cual es en su conjunto un cuadro de costumbres venecianas de Carnaval, en el que los únicos personajes en escena son representantes del pueblo. Por más de un motivo tuvo mucha razón una antigua alumna mía al señalar que la última comedia lacrimosa no se compuso hasta 1843; pues, aunque para esas fechas Cecilia la cieguita de Antonio Gil y Zárate, era una excepción rezagada ${ }^{20}$, el género sentimental sí sobrevivió como el mismo mesodermo del drama romántico del ochocientos.

20 Joan Lynne Pataky Kosove, The «Comedia Lacrimosa» and Spanish Romantic Drama, London, Tamesis, 1977, pp. 98-101. 